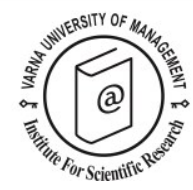

\title{
The Pink Store: A unique tourism enterprise at the US-Mexico border
}

\author{
Tomás Cuevas ${ }^{1}$, Dani Blasco ${ }^{2}$ and Dallen J. Timothy ${ }^{3 *}$
}

Received: 23/11/2015 Accepted: 05/12/2015

\footnotetext{
1 ICSA, Universidad Autónoma de Ciudad Juarez, Av. Heroico Colegio Militar s/n, Zona Chamizal, 32310 Ciudad Juárez, CHIH, Mexico; phone: +52 (656) 6883800 Ext. 3683 - 3745; email: tcuevas@gmail.com

${ }^{2}$ Faculty of Tourism, Business Management Department, University of Girona, Plaça Josep Ferrater i Móra, 1 , 17004 Girona, Spain; phone: +34 972419 512; email: dani.blasco@udg.edu

${ }^{3}$ School of Community Resources and Development, Arizona State University, 411 N. Central Avenue, Suite 550, Phoenix, AZ 85004, USA; phone: +1 602496 1566; email: dtimothy@asu.edu

* Corresponding author
}

\section{Abstract}

This case study examines the unique situation of the Pink Store in Palomas, Chihuahua, Mexico, a small town and crossing point on the US-Mexico frontier. This case is unique and interesting because of how managers have recognised the value of the international border and capitalised on it as a positive experience for day-trippers from the United States. Consequently, they developed certain practices that have positioned the store as a well-recognised icon in the larger region, allowing them to take advantage of the border and the commercial opportunities it creates. The management actions are both product- and service-led, and marketing-oriented. As a result, the Pink Store represents a distinctive border attraction that is characterised as an all-inclusive attraction, exotic and foreign, yet secure and oriented to its major market: residents of the USA.

(C) 2016 Varna University of Management. All rights reserved

Keywords: international borders, border crossing, tourism enterprise, shopping, novelty, repeat customers, anchor attraction.

Citation: Cuevas, T., D. Blasco and D. Timothy (2016) The Pink Store: A unique tourism enterprise at the US-Mexico border. European Journal of Tourism Research 13, pp. 122-131

\section{Introduction}

Depending on the socio-economic and political relationships between neighbouring countries, borders vary in their level of permeability. As such, administrative processes performed at points of entry can range from very strict and time-consuming customs and immigration procedures to rudimentary ones, or in some instances, no formalities at all. For example, entering the United States from Mexico usually entails long queues for passport and visa checks, questioning, and car inspections, while crossing borders between Schengen states in Europe is usually done with no inspection at all. Regardless of the degree of strictness, crossing a border can be an exciting proposition and an important part of the journey for many travellers (Medvedev, 1999; Gelbman 
\& Timothy, 2010; Timothy, 1995). Border checkpoints have been considered both spaces and nonplaces (Kawash, 2003; Tawil-Souri, 2011), and visiting or crossing them brings something extra to the experience. This translates into many tourists photographing the border, buying souvenirs from the 'other side', and telling of their experiences to friends and family at home. At many less permeable borders, tourists' interests in crossing the border are in some cases not met with business interest in delivering services immediately adjacent to the border. This may be largely owing to administrative and security restrictions performed at boundary checkpoints. In many Mexican border towns, however, there are and have long been shops and restaurants adjacent to the border and extending a few hundred meters from it into the country. These shops and restaurants have become an important part of the commercial districts, tourism landscapes and physical structures of border towns (Arreola \& Curtis, 1993; Arreola \& Madsen, 1999).

These days there is a general perception in the US that travelling to Mexico is unsafe and risky. This is perpetuated by government travel warnings and extensive media coverage of drug cartel violence south of the border. In addition, US citizens crossing to Mexico perceive different levels of risk, depending on whether or not they are first-time or repeat visitors (Canally \& Timothy, 2007). These differing risk patterns may constitute a challenge to marketing strategies (Karamustafa, Galia \& Reichel, 2013) and affect tourism demand for Mexico, including its border communities. The result is that the presence of tourism products and services that have a border location advantage have declined significantly in recent years (McGuire, 2013; Stevenson, 2013).

This case study describes how a private enterprise located in Palomas, Chihuahua, Mexico, has identified the value of the bordercrossing experience for some American tourists, and thus has found ways to deliver unique services to ease access and alleviate security concerns among US citizens visiting the shop and restaurant known as the Pink Store. In broad terms, the paper addresses factors that contribute to the success of a certain borderland shop and restaurant.

\section{Tourism activities and crossing borders}

Throughout history, borders have been considered regions of economic disadvantage because they lie on national margins, peripheral to the core of political and socioeconomic activity of nation-states (Nagy, Nagy \& Timár, 2012). Thus, they have been traditionally avoided by both public and private sectors, owing to the complex security-oriented state bureaucracy focused on these areas of potential conflict (Arieli, 2009) and because they are often sparsely populated. However, more recently, different activities, such as trading, labour and education migration, leisure mobility, and tourism have positively contributed to new configurations of national boundaries and neighbourly relations (Hall, 2000). Borders are crossed daily by millions of people, for a number of different leisure and economic purposes, with shopping being one of the most popular. Timothy and Butler (1995) distinguished seven factors that contribute to the growth of cross-border shopping: favourable exchange rates, lower taxes, competitive distribution channels due to economies of scale, wider selections of goods and services, better customer service, longer opening hours and days, and the entertainment factor of shopping abroad.

People are more likely to cross for shopping if they live near the border, because there is a strong correlation between distance to the destination and the level of familiarity with the border, with people in proximal areas visiting more often than those who live further away (Timothy, 2001; Timothy \& Butler, 1995). Frequency of travel (past travel experience and frequency of visits) is another dimension of familiarity. This sense of familiarity (including a sense of security) with what lies on the other side can diminish the barrier effect of the border (Canally \& Timothy, 2007; Leimgruber, 1988). In contrast to the concept of familiarity, some authors have suggested that the concept of novelty is an intrinsic motivation to seek and consume new products and services, and visit new places (Chang, Wall \& Shi-Ting, 2006; Chang \& Chiang, 2006). This is also a likely factor in many people's motivations for crossing 
borders (Basala \& Klenosky, 2001; Lord, Putrevu \& Shi, 2008).

One important motive for crossing borders by people who live nearby is dining and shopping on the other side. As Timothy (2001: 59) noted, "the fact that many border shoppers eat out in restaurants and visit museums, movie theatres, historic sites, and sporting events while abroad, indicates that the trip does in fact include other forms of pleasure seeking". Similarly, in their commentary, Stinson and Bourette, (1998: 1) noted that many Americans travelled $40-50 \mathrm{~km}$ on a regular basis just to eat at a Canadian restaurant (cited in Timothy, 2001: 65). Lord, Putrevu and Parsa (2004) argue that consumers who cross national borders to dine potentially participate in multiple consumption experiences. Thus, crossing borders for dining and shopping can be motivated by familiarity for some (i.e. repeat visitors) and novelty for others (i.e. first-time consumers).

Lord et al. (2004), Lord, Putrevu and Zheng (2006), and Timothy (2001) identified several variables that motivate crossing borders to dine and shop: value, variety, awareness, ease of crossing, proximity to the border, and perceived differences between restaurants and shops on opposite sides. They also identified variables that inhibit crossing international borders to dine and shop: ethnocentrism, affective/social considerations, border formalities, and tax restrictions to name but a few.

Regarding the southern side of the Mexico-US border, there are a number of places that have been popular destinations for people who live near the border and cross for drinking, eating and other diversions (Arreola \& Curtis, 1993; Timothy \& Canally, 2008). In fact, eating authentic Mexican food and purchasing Mexican products are considered significant motives for visiting the border (Canally \& Timothy, 2007; Timothy \& Canally, 2008). Shopping and dining in Mexico have long been an important attraction for Americans, Canadians and other tourists visiting the USMexico border area (St. John, 2009; Walker, 2013).

Table 1. Official crossings into the US from Mexico (2012)

\begin{tabular}{|c|c|c|c|c|c|c|}
\hline Position & Crossing point & Pedestrians & By car & By bus & Subtotal & $\%$ \\
\hline 1 & Tijuana/San Ysidro & 8134479 & 19944913 & 583589 & 28662981 & $18.02 \%$ \\
\hline 2 & Ciudad Juárez/EI Paso & 6090841 & 15908404 & 435560 & 22434805 & $14.10 \%$ \\
\hline 3 & Nuevo Laredo/Laredo & 3206372 & 8767939 & 989205 & 12963516 & $8.15 \%$ \\
\hline 4 & Tijuana/Otay Mesa & 3205792 & 9297601 & 163672 & 12667065 & $7.96 \%$ \\
\hline 5 & Mexicali/Calexico & 4885868 & 6981401 & 0 & 11867269 & $7.46 \%$ \\
\hline 6 & Reynosa/Hidalgo & 2073485 & 9484335 & 302789 & 11860609 & $7.46 \%$ \\
\hline 7 & Matamoros/Brownsville & 2107145 & 8270359 & 51326 & 10428830 & $6.56 \%$ \\
\hline 8 & Nogales/Nogales & 3238929 & 5729756 & 159472 & 9128157 & $5.74 \%$ \\
\hline 9 & $\begin{array}{l}\text { San Luis Rio Colorado/San } \\
\text { Luis }\end{array}$ & 2497321 & 4575051 & 339 & 7072711 & $4.45 \%$ \\
\hline 10 & Mexicali/Calexico East & 318599 & 5530414 & 92630 & 5941643 & $3.74 \%$ \\
\hline 11 & Piedras Negras/Eagle Pass & 734215 & 4620413 & 23156 & 5377784 & $3.38 \%$ \\
\hline 12 & Agua Prieta/Douglas & 1198838 & 2610492 & 19670 & 3829000 & $2.41 \%$ \\
\hline 13 & $\begin{array}{l}\text { Nuevo Progreso, Rio } \\
\text { Bravo/Progreso }\end{array}$ & 827708 & 2149675 & 0 & 2977383 & $1.87 \%$ \\
\hline 14 & Ciudad Acuña/Del Rio & 90733 & 2560427 & 39 & 2651199 & $1.67 \%$ \\
\hline 15 & Tecate/Tecate & 702742 & 1512828 & 1723 & 2217293 & $1.39 \%$ \\
\hline 16 & Algodones/Andrade & 893191 & 828660 & 0 & 1721851 & $1.08 \%$ \\
\hline 17 & Miguel Aleman/Roma & 266021 & 1275578 & 12478 & 1554077 & $0.98 \%$ \\
\hline 18 & Ojinaga/Presidio & 78768 & 1163393 & 8558 & 1250719 & $0.79 \%$ \\
\hline 19 & Jeronimo/Santa Teresa & 104519 & 900563 & 3039 & 1008121 & $0.63 \%$ \\
\hline 20 & Palomas/ Columbus & 264198 & 546118 & 16758 & 827074 & $0.52 \%$ \\
\hline 21 & $\begin{array}{l}\text { Ciudad Camargo/Rio Grande } \\
\text { City }\end{array}$ & 47274 & 672256 & 0 & 719530 & $0.45 \%$ \\
\hline 22 & Caseta/Fabens & 61216 & 618672 & 0 & 679888 & $0.43 \%$ \\
\hline 23 & Sonoyta/Lukeville & 39513 & 581467 & 2086 & 623066 & $0.39 \%$ \\
\hline 24 & Naco/Naco & 72896 & 493205 & 547 & 566648 & $0.36 \%$ \\
\hline \multirow[t]{2}{*}{25} & Sasabe/Sasabe & 977 & 25665 & 0 & 26642 & $0.02 \%$ \\
\hline & & & & Total & 159057861 & $100.0 \%$ \\
\hline
\end{tabular}

Source: US Department of Transportation, Bureau of Transportation Statistics (2013) 


\section{Palomas, Mexico, and the Pink Store}

The United States is one of the largest tourism markets in the world. It shares a 3,153-km frontier with Mexico to the south, with 47 crossing points, of which 24 receive more than 500,000 crossings each year (Table 1).

Palomas and Columbus represent a minor crossing point on the border, ranking $20^{\text {th }}$ of all Mexico-US border crossings, with 827,074 people crossing in 2012. The busiest are San Ysidro/San Diego-Tijuana, with over 28.5 million crossings, and EI Paso-Ciudad Juárez, with almost 22.5 million crossings in 2012.

Palomas is a small village in the state of Chihuahua with approximately 5,748 inhabitants (Instituto Nacional de Estadíca y Geografía, 2005). Columbus, New Mexico, is the closest community on the US side, situated $4.5 \mathrm{~km}$ from the border with a population of 1,664 inhabitants (US Census Bureau, 2010). Palomas and Columbus are fairly well known among history buffs because of the historical incident involving Pancho Villa and a group of 400 riders, who attacked Columbus in 1916 during the Mexican Revolution. At that time, Columbus was a customs station for the US government. While Pancho Villa's raid lasted only a few hours, it remains the first, and one of very few, foreign attacks on US national territory in modern history.

Today, Palomas is a non-descript village that hugs the US border, and its sole purpose is a transit location with customs services. It is relatively isolated in the desert and located at considerable distances from any other major Mexican towns $(110 \mathrm{~km}$ to Ciudad Juárez and $150 \mathrm{~km}$ to Nuevo Casas Grandes). It attracts many day-trippers from the southwestern United States who come to purchase lessexpensive pharmaceuticals or receive dental and eye care at a handful of pharmacies, dental practices and optometrists. They also come to dine and shop at the Pink Store, which forms the economic spine of the community and serves as the anchor tourist attraction for the entire village.

\section{The Pink Store}

The assessment of the Pink Store situation is based upon multiple visits to the store by the authors during the past five years. These visits have included systematic interviews with store workers and its owners and unstructured interviews with customers to understand their points of view about the services and the relationship between the shop/restaurant and the international border.

Between 2010 and 2014, many Pink Store customers were observed and interviewed near the border in Deming, Silver City, Las Cruces and El Paso. The majority (between $50 \%$ and $60 \%$ ) of them are repeat visitors. While most of the Pink Store's clients are Americans, the business has also received clients from around the world including Germany, Australia, Japan, Poland, Spain, and various other countries.

The Pink Store is located in Mexico only 146 metres from the borderline, on the main street of Palomas. It was founded over two decades ago and today is the main souvenir store and one of a few restaurants located in the village. Most of its clients are US residents who cross by foot or are picked up at the car park on the US side. The average age is over 40 , with many being retirees, and generally they have high purchasing power. Most of the shop's clients are repeat customers who enjoy visiting for various reasons, including familiarity with the destination (Karamustafa et al., 2013), but primarily for the food and merchandise. The main market extends some 320 kilometres around (north of the border) with a catchment population of around two million people in Tucson (Arizona), El Paso (Texas) and Las Cruces (New Mexico), as well as dozens of smaller towns and cities (Figure 1). At its inception, the store was promoted at RV parks in the southwestern US, where many seniors and retirees spent their winters. Word of mouth was the primary promotional medium, and although demand in the beginning was only a trickle, word of mouth has been very effective in spreading the fame of the Pink Store. RV (caravan) travellers and seasonal visitors from the north (i.e. snowbirds) have been the most reliable first-time and repeat customers. In that community, word spreads easy and rapidly about the Pink Store and what it has to offer.

The store has four interactive areas: the cashier; the showroom filled with crafts, 
jewellery, tequila and liqueurs, and rustic furniture; a dining room; and attached businesses in the same shopping centre area, including dental and optometry services and a travel agency. The dining room has a capacity of 108 , and service hours are from 10:00 to $17: 00$.

The owner has a long history of tourism involvement in the community. His parents started about 40 years ago with a grocery store, a block from the current location. Over time the grocery store was transferred to his daughter and her husband. The son had experience in managing crafts markets, which he incorporated into the current handicraft enterprise.

The Pink Store has undergone many changes since it opened in 1988, with three distinct periods being identified (see Figure 2). The business began as an arts and crafts shop for tourists and a small grocery store for local people. Later, the owner decided to open a

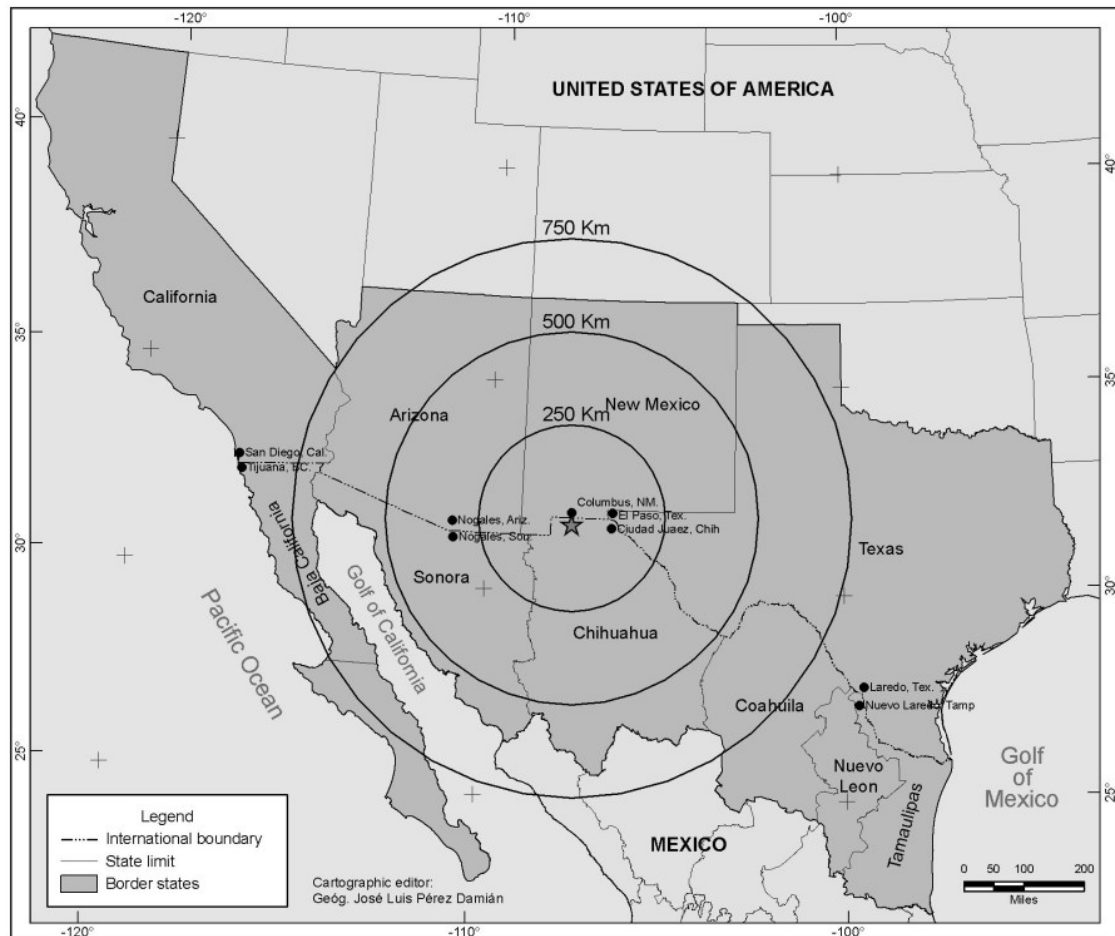

Figure 1. Situation of the Pink Store at Palomas and its catchment area

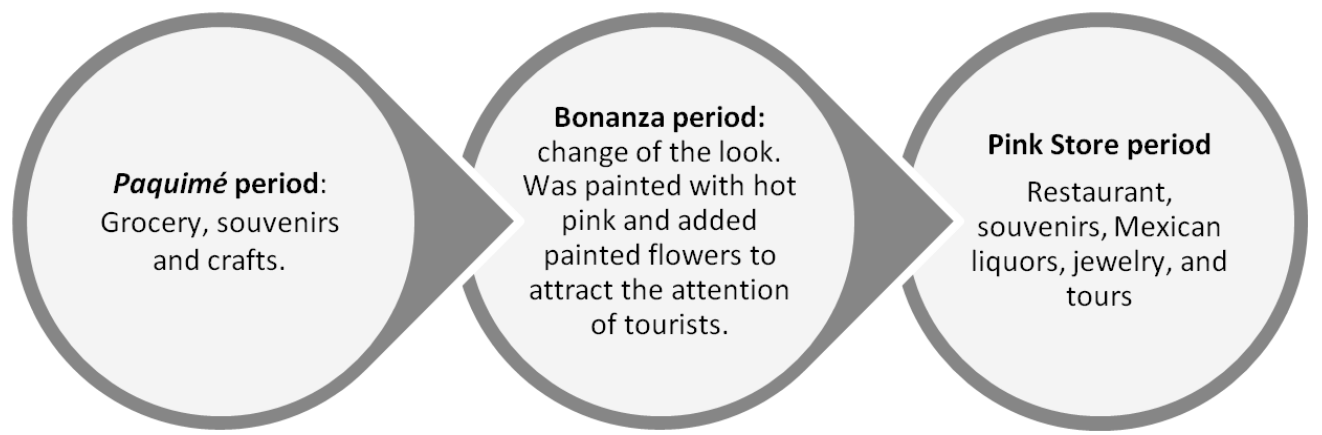

Fiqure 2. Evolution of the Pink Store, 1988-2015 
small restaurant in an extension of the shop. Since then, there have been several expansions that have resulted from the store's iconic status. Through the years, the owner has tried different products and services (e.g. opening a disco at one point), some of which have succeeded, while others have not. The latest product is the organisation of excursions and trips to various Mexican cities and historic sites in the general area. It is important to note that this expansion process has been driven by trial and error and, to a certain extent, success has come by accident. The original shop and small restaurant was called Paquimé, which soon after changed to Bonanza, because of the difficulty of pronouncing Paquimé by Americans. Later, the store was painted Mexican pink to lend a sense of tradition and authenticity, since this is one of the traditional colours used in clothing and other elements of Mexican material culture. In response to the establishment's new colour, clients began calling it "the Pink Store"-a term of endearment that has since become the official name of the store and restaurant.

Nowadays, the store has grown so much in popularity that competition is extremely difficult. Its reputation extends far into the US and into Mexico, and for other potential competitors, opening a similar business in size, quality and quantity of items and services offered, would be prohibitively expensive and commercially risky. The owner, however, has recognised the need to share part of the benefits with local stakeholders by leasing business space at the nearby Pink Store Plaza and hiring other villagers. Finally, political cycles have favoured the development of the village of Palomas, turning it into an ostensibly larger "town" with publicly-provided essential services and infrastructure. The Pink Store is the tourism anchor for the entire village. Its owner finances much of the village infrastructure singlehandedly, and essentially all earnings in the community via cross-border tourism derive directly or indirectly from the Pink Store.

\section{The Uniqueness of the Pink Store}

The uniqueness of the Pink Store from other border shops in other border towns can be seen from two different perspectives: the store's merchandise and services, and its marketing strategies. The services/ merchandise and marketing advantages relate directly to the Pink Store's border location and make the business dynamic and versatile.

Regarding the products and services at the Pink Store, visitors find a wide variety of Mexican souvenirs, jewellery, and arts and crafts from many different regions of the country. Visitors also frequent a well-regarded restaurant that offers traditional 'old' tastes, based on nineteenth-century Mexican gastronomic principles and ingredients, including potatoes, dried chillies, meat, beans, cheese, and flour tortillas. In addition, the store has a wide selection of Mexican spirits, such as tequila and sotol, both for tasting and for buying. In the adjacent Pink Store Plaza customers can, according to the store's website, do "Everything you came to Mexico to do": visit a pharmacy, get dental work done, and purchase new glasses (The Pink Store, 2015: np).

Perhaps the most unique service provided by the Pink Store is transfers by golf cart to and from the borderline for customers who cross by foot, or to the car park located on the US side. Pink Store owners have negotiated special arrangements to allow the golf cart to cross the border many times each day to pick up customers waiting at their cars on the US side of the boundary. This is itself a very unique arrangement that is much appreciated by visiting American consumers. This service has two objectives. First, customers do not need to cross with their own cars, thus avoiding the need to purchase Mexican insurance and avoiding long queues returning to the United States. Second, visitors are accompanied by Pink Store employees, which, makes them feel safer and more secure.

As noted earlier, the Pink Store owners have also tried to add a more diversified product beyond handicrafts and food, with varying levels of success. They are currently engaged in offering tours from the Pink Store to historic sites and in proximate locations in Chihuahua, such as Paquimé Ruins (a UNESCO World Heritage Site and only an hour away), Ciudad Juárez, and Casas Grandes. 
Once at the shop, customers are offered a Mexican margarita cocktail free of charge while wandering the corridors of the store. In addition, the store packages and ships furniture and larger items to customers' homes in the United States. This helps the tourists avoid border congestion, issues with customs, and the need to carry heavy items back to their cars.

Finally, most employees in the restaurant are Mexicans, which lends a degree of exoticness and authentic Mexicanness that is characterised by friendly and hospitable service. A few of the supervisors are Americans, which simultaneously tends to convey a sense of trust and confidence for many customers. All employees are required to speak English fluently, and they are trained in the standards and attributes of the service quality expected by their neighbours to the north.

The second way the Pink Store is unique is its marketing strategies. First, behind the colourful name is an enterprise, clearly oriented to its well-defined US travel market. In fact, the store's website is available only in English, and there is very little information available about the Pink Stork in Spanish on the Internet. As a result, few Mexicans outside Palomas or northern Chihuahua know the place, while many Americans from throughout the southwestern states are familiar with it because of its regional reputation. The owners have attempted to develop cross-border collaboration with communities in the US catchment area with varying degrees of success. They have participated in fairs and exhibitions and made donations of in-kind services to various causes on the US side of the border.

Relatedly, the second strategy has hardly been a strategy at all but rather a hands-off approach. The Pink Store owners have expended very little (for a brochure and website design) on marketing funds, because their reputation for food, merchandise and service has been bolstered sufficiently by word of mouth among US-based consumers. There have been no widespread efforts to market the store or village on the US side of the border.
Third, management has capitalised on Pancho Villa's historic invasion, both to add another attraction for the village, as well as to be more visible and branded to offset the effects of Palomas' remote location. The Pancho Villa heritage of the area is well-known throughout the United States and adds an additional cultural element to the Pink Store/Palomas experience.

The store also uses the quietness and isolation of Palomas in its brochure, website and public relations to increase the sense of security for American customers. It is far from the difficulties of Ciudad Juárez and other larger border cities, which gives it an intrinsic sense of security for American border crossers.

Finally, to play into the notion of "authentic Mexico", management has hired a native Tarahumara woman to welcome visitors at the door during the busiest seasons. While this woman is not indigenous to the immediate area, she does help provide an "exotic" sense of native old Mexico.

\section{Conclusions}

Borders have different degrees of permeability in different parts of the world, ranging from no procedures, or simple procedures, to very complex bureaucratic and security screening processes. Despite the difficulties of crossing, tourists generally have a positive attitude about the idea of traversing borders, which becomes an exciting experience for many (Medvedev, 1999; Timothy, 1995, 2001). It is fair to say that in the case of the Mexico-US border, a less permeable divide with strict security controls and administrative restrictions, establishing businesses on one side that are meant to attract customers from the other side is a significant challenge. The strict formalities often dissuade potential clients from crossing (Canally \& Timothy, 2007).

Because of management operations and decisions in relation to the border, the Pink Store represents a case of success in how small businesses can take advantage of the presence of a border by adopting unique actions and strategies (Arreola, 1999; Dutta, 2010; Jayawardena, White \& Carmichael, 2008; Timothy \& Gelbman, 2015). In terms of 
the product and service delivery, the store is a sort of all-inclusive concept with a wide variety of products ranging from food and shopping to travel services. To ensure positive visitor experiences management has made concerted efforts to be both exotic/foreign and safe. Service standards and pricing have been adapted to meet the needs and expectations of visiting US residents. All in all, there is no other shop like the Pink Store in town, or anywhere else along this border that the authors are aware of. In this sense, the Pink Store has a de facto monopoly because of its reputation and variety of offerings; no other establishment can compete, especially in such a small community. As a result, it has become popular and well recognised throughout the southwestern USA. The Pink Store is the tourism icon of Palomas and provides the "Mexicolandia" encounter that is so often desired by Americans who desire the experience but do not want to venture far into Mexico (Arreola, 1999; Stolk, 2004).

From a management perspective, it is interesting to note that the Pink Store represents a paradigmatic example of the way in which few businesses are run in Mexico, based on day-by-day trial and error rather than on previously-programmed processes, the latter being common among most Mexican border town shops that sell standardised products and services. Moreover, the Pink Store is an example of a small enterprise that prospers by embracing its border location and cross-border networks (Cuevas Contreras, Carmona-Vega, and Zizaldra Hernández, 2012) rather than bemoaning the border the way many shops have done along the same frontier in different locations. The Pink Store's factors of success include providing a "Mexican experience" within a short walking distance of the border, free transportation to and from the border, quality food and handicrafts, international shipping services, arranging inland tours, and providing all assistance in English-services that most other border merchants in larger border towns, such as Tijuana, Juárez, and Nogales, do not offer. As well, its publicity efforts have focused on its American niche market, word of mouth, local heritage and the village's safe environmentlargely a result of its isolation from the larger border conurbations.
Through these efforts, the Pink Store has earned the loyalty of its largely repeat customers from the US side of the frontier and has expended next to nothing on marketing. It would behove other attractions and destinations along the US-Mexico border, and other borders throughout the world, to adopt similar factors of success as they pertain to their own unique border circumstances.

\section{Acknowledgements:}

The authors would like to thank Sergio Romero, owner of the Pink Store, for his time and the time of the staff. We would also like to thank José Luís Pérez Damián (Universidad Autónoma de Mexico) for his cartographic assistance.

\section{References}

Arieli, T. (2009) Israeli-Palestinian border enterprises revisited. Journal of Borderlands Studies 24 (2), 1-14

Arreola, D. D. (1999) Across the street is Mexico: invention and persistence of the border town curio landscape. Yearbook of the Association of Pacific Coast Geographers 61, 9-41

Arreola, D. D., J. R. Curtis (1993) The Mexican border cities: landscape anatomy and place personality. Tucson: University of Arizona Press.

Arreola, D. D., K. Madsen (1999) Variability of tourist attractiveness along an international boundary: Sonora, Mexico, border towns. Visions in Leisure and Business 17 (4), 19-31

Basala, S., D. Klenosky (2001) Travel-style preferences for visiting a novel destination: a conjoint investigation across the novelty continuum. Journal of Travel Research 40, 172-182

Canally, C., D. J. Timothy (2007) Perceived constraints to travel across the US-Mexico border among American university students, International Journal of Tourism Research 9, 423-437

Chang, J., C. H. Chiang (2006) Segmenting American and Japanese tourists on novelty-seeking at night markets in Taiwan. Asia Pacific Journal of Tourism Research 11 (4), 391-406 
Chang, J., G. Wall, C. Shi-Ting (2006) Novelty seeking at aboriginal attractions. Annals of Tourism Research 33 (3), 729-747

Cuevas Contreras, T., E. G. Carmona-Vega, I. Zizaldra Hernández (2012) Turismo transfronterizo reticular, exploración del caso como ciudades hermanas: Ciudad Juárez, Chihuahua-El Paso, Texas. In Cuevas Contreras, T., A. Palafox Muñoz (eds.) (2012) Turismo en la frontera del conocimiento: Entre la modernidad y la posmodernidad. Ciudad Juárez: Universidad Autónoma de Ciudad Juárez, 75-95

Dutta, G. (2010) Internationalization of small businesses of border region: a study of the determinants. Journal of Borderlands Studies 25 (3/4), 50-63

Instituto Nacional de Estadística y Geografía (2005) Conteo de población y vivienda. URL: http://www.inegi.org.mx/ (Accessed on 01.10 .2013 )

Gelbman, A., D. J. Timothy (2010) From hostile boundaries to tourist attractions. Current Issues in Tourism 13 (3), 239-259

Hall, D. (2000) Cross-border movement and the dynamics of transition processes in Southeastern Europe. GeoJournal 50 (23), 249-253

Jayawardena, C., A. White, B. Carmichael (2008) Binational tourism in Niagara: insights, challenges and the future. International Journal of Contemporary Hospitality Management 20 (3), 347-359

Karamustafa, K., F. Galia, A. Reichel (2013) Risk perceptions of a mixed-image destination: the case of Turkey's first-time versus repeat leisure visitors. Journal of Hospitality Marketing \& Management 22 (3), 243-268

Kawash, S. (2003) Nation, place and placelessness: Identity, body and geography in the case of Palestine. Croatian Journal of Ethnology and Folklore 40 (1), 37-48

Leimgruber, W. (1988) Border Trade: The boundary as an incentive and an obstacle to shopping trips. Nordia 22, 53-60

Lord, K. R., S. Putrevu, H. G. Parsa (2004) The cross-border consumer: investigation of motivators and inhibitors in dining experiences. Journal of Hospitality \& Tourism Research 28 (2), 209-229
Lord, K. R., S. Putrevu, Y. Z. Shi (2008) Cultural influences on cross-border vacationing. Journal of Business Research 61 (3), 183-190

Lord, K. R., S. Putrevu, S. Y. Zheng (2006) Cross-border restaurant patronage: Cultural determinants of perception and satisfaction. International Journal of Hospitality and Tourism Administration 6 (4), 33-47

McGuire, R. H. (2013) Steel walls and picket fences: rematerializing the U.S.-Mexican border in Ambos Nogales. American Anthropologist 115 (3), 466-480

Medvedev, S. (1999) Across the line: borders in post-Westphalian landscapes. In Eskelinen, H., I. Liikanen, J. Oksa (ed.) (1999) Curtains of Iron and Gold: Reconstructing Borders and Scales of Interaction. Aldershot: Ashgate, 43-56

Nagy, G., E. Nagy, J. Timár (2012) The changing meaning of core-periphery relations in a non-metropolitan "urban region" at the Hungarian-Romanian border. The Planning Review 48 (2), 93105

St. John, R. (2009) Selling the border: trading land, attracting tourists, and marketing American consumption on the Baja California border, 1900-1934. In McCrossen, A. (ed.) (2009) Land of Necessity: Consumer Culture in the United States-Mexico Borderlands. Durham, NC: Duke University Press, 113-142

Stevenson, M. (2013) Mexico may drop out of top 10 tourist destinations. Associated Press. URL:

http://bigstory.ap.org/article/mexico-maydrop-out-worlds-tourism-top-10 (Accessed on 24.10.2013)

Stinson, M., S. Bourette (1998) Dollar sinks to lowest ever: Americans flock to Canadian border towns to wine and dine at a discount. The Global and Mail (Toronto), 39 January: 1

Stolk, H. (2004) 'This is not Mexico, this is the border': discourses on authentic Mexican culture in Tijuana. Etnofoor 17 (1/2), 227242

Tawil-Souri, H. (2011) Qalandia Checkpoint as Space and Nonplace, Space and Culture 14 (1), 4-26 
The Pink Store (2015) The Pink Store. URL: http://www.thepinkstoremexico.com/PinkSt oreHome.html (Accessed on 30.08.2015)

Timothy, D. J. (1995) Political boundaries and tourism: borders as tourist attractions. Tourism Management 16 (7), 525-532

Timothy, D. J. (2001) Tourism and political boundaries. London: Routledge.

Timothy, D. J., R. W. Butler (1995) Crossborder shopping: a North American perspective. Annals of Tourism Research 22 (1), 16-34

Timothy, D. J., Canally, C. (2008) The role of the US-Mexico border as a destination: student traveller perceptions. Tourism Analysis, 13(3): 259-269

Timothy, D. J., Gelbman, A. (2015) Tourist lodging, spatial relations, and the cultural heritage of borderlands. Journal of Heritage Tourism, 10(2): 202-212

US Census Bureau (2010) Columbus village, New Mexico. URL: http://factfinder2.census.gov/faces/nav/jsf/ pages/community_facts.xhtml (Accessed on 01.10.2013)

US Department of Transportation, Bureau of Transportation Statistics (2013) Border crossing/entrydata. URL: http://transborder.bts.gov/programs/interna tional/transborder/TBDR_BC/TBDR_BC_I ndex.html (Accessed on 09.10.2014)

Walker, M. A. (2013) Border food and food on the border: meaning and practice in Mexican haute cuisine. Social \& Cultural Geography 14 (6), 649-667. 